\title{
ANALISIS PENGARUH VARIASI BAHAN BAKAR BIOMASSA TERHADAP MAMPU NYALA DAN KANDUNGAN TAR PADA REAKTOR GASIFIKASI TIPE UPDRAFT
}

\author{
(1) Abrar Ridwan, ${ }^{(2)}$ Budi Istana \\ ${ }^{(1.2)}$ Prodi Teknik Mesin Universitas Muhammadiyah Riau Pekanbaru \\ ${ }^{(1)}$ Email : abrar.ridwan@umri.ac.id \\ Jl. Tuanku Tambusai Ujung - Pekanbaru
}

\begin{abstract}
ABSTRAK
Pada Gasifikasi tipe Updraft bahan bakar dimasukkan dari bagian atas dan udara masuk pada bagian bawah reaktor.Kekurangan dari gasifikasi tipe Updraft adalah gas yang keluar dari reaktor berada pada kondisi temperatur rendah $\left(<500{ }^{\circ} \mathrm{C}\right)$, serta membawa tar yang terkondensasi serta minyak yang berasal dari proses pirolis. Pada penelitian ini akan membandingkan bahan bakar biomassa Tempurung Kelapa dan Pelepah Kelapa Sawit dari segi mampu nyala dan kandungan tar. Bahan bakar tersebut dibakar didalam reaktor sampai Syngas terproduksi, setelah Syngas berproduksi pada reaktor, penarikan tar dapat dilakukan dan penarikan tar dihentikan apabila Syngas pada reaktor telah padam. Dari hasil penelitian, didapat mampu nyala dari biomassa Tempurung kelapa selama 43 menit 14 detik sedangkan biomassa Pelepah kelapa sawit selama 10 menit 26 detik.Berat tar kering hasil proses gasifikasi yang ditimbang menggunakan timbangan digital pada Biomassa Tempurung kelapa adalah 8,99 g, sedangkan pada Biomassa Pelepah kelapa sawit adalah 4,62 g. Banyaknya gas sampel yang disedot pompa vakum pada Biomassa Tempurung kelapa adalah 138,58 liter sedangkan pada Biomassa Pelepah kelapa sawit adalah 133,88 liter. Massa tar pada setiap liter gas sampel Biomassa Tempurung kelapa adalah 0,064 gram/liter sedangkan Biomassa Pelepah kelapa sawit adalah 0,034 gram/liter.
\end{abstract}

\section{Kata kunci : Gasifikasi tipe updraft, Mampu nyala, Kandungan Tar}

\section{PENDAHULUAN}

Kebutuhan bahan bakar untuk energi di Indonesia saat ini semakin meningkat seiring peningkatan jumlah penduduk dan kemajuan industri. Di sisi lain cadangan minyak bumi di Indonesia kian menipis, untuk mengatasi krisis energi yang terjadi saat ini diperlukan sebuah usaha untuk mencari energi alternatif lain yang lebih murah, mudah dicari, dan dapat di perbaharui. Energi alternatif yang populer digunakan saat ini adalah biomassa , (Lailun, dkk, 2012).

Gasifikasi Biomassa adalah salah satu cara yang dapat dilakukan untuk memperoleh energi alternatif selain dari energi fosil. Bahan biomassa adalah bahan yang dapat diperbaharui dalam kurun waktu yang relatif singkat dan juga ketersediaanya di Indonesia yang berlimpah, (Higman and Burg, 2003).

Penelitian dilakukan pada reaktor gasifikasi jenis updraft dengan variasi bahan bakar biomassa yang berbeda yaitu Tempurung kelapa dan Pelepah kelapa sawit untuk mengetahui biomassa mana yang mampu menghasilkan gas mampu bakar yang baik Tempurung kelapa dan Pelepah kelapa sawit mudah dicari di Provinsi Riau ini, dengan melihat pertimbangan tersebut maka dipilih variasi bahan bakar yang akan diuji adalah Tempurung kelapa dan pelepah kelapa sawit. Pada penelitian sebelumnya (Dede Yefandri, 2017) yang berjudul "Analisa Pengaruh Kandungan Tar Pada Gasifikasi tipe Updraft Terhadap Perlakuan Udara Panas Masuk Reaktor dan Variasi ER 
(Ekivalen Rasio)". Penelitan tersebut meneliti kandungan tar pada reaktor gasifikasi tipe updraft, namun metode pengujian kandungan tar tersebut sangat sederhana dan tidak sesuai dengan standar. Maka dari itu penulis mendapat ide untuk merancang sebuah penelitian tentang gasifikasi tipe updraft dengan pengujian kandungan tarnya yang sesuai dengan standar CEN (ComiteEuropeen de Normalisation).

\section{LANDASAN TEORI}

Gasifikasi adalah proses pengkonversian bahan bakar padat menjadi gas mampu bakar $\left(\mathbf{C O}, \mathbf{C H}_{4}, \mathbf{H}_{2}\right)$ melalui proses pembakaran dengan suplai udara terbatas yaitu antara 20\% hingga $40 \%$ udara stoikiometri. Reaktor tempat terjadinya proses gasifikasi disebut gasifier. Selama proses gasifikasi akan terbentuk daerah proses yang dinamakan menurut distribusi suhu dalam reaktor gasifier. Daerah-daerah tersebut adalah: Drying, Pyrolisis, Reduksi dan Combustion. Masing-masing daerah terjadi pada rentang suhu antara $100{ }^{\circ} \mathrm{C}$ hingga $300{ }^{0} \mathrm{C}, 300{ }^{0} \mathrm{C}$ hingga $900{ }^{0} \mathrm{C}, 400{ }^{0} \mathrm{C}$ hingga $900{ }^{0} \mathrm{C}$, dan $900{ }^{0} \mathrm{C}$ keatas. (Bambang, dkk, 2009). Gas hasil dari proses gasifikasi disebut biogas, producer gas atau syngas. Ada 3 macam jenis dari gasifikasi yaitu Gasifikasi tipe Downdraft ,Gasifikasi tipe Updraft dan Gasifikasi tipe Crossdraft.

Pada tipe Updraft ini umpan dimasukkan pada bagian atas reaktor dan bergerak kebawah melewati zona pengeringan, pirolisis, reduksi, dan oksidasi. Sedangkan udara masuk pada bagian bawah dan gas keluar pada bagian atas. Keunggulan tipe ini yaitu kesederhanaannya, tigkat pembakaran arang yang tinggi, pertukaran panas internal sehingga suhu gas keluar rendah, dan efisiensi gasifikasi yang tinggi. Selain itu bahan baku yang diumpankan dapat berada pada kondisi kadar air yang cukup tinggi $(50 \%$ wb). Kekurangannya, producer gas yang keluar dari reaktor berada pada kondisi temperatur rendah $\left(<500{ }^{0} \mathrm{C}\right)$, membawa tar yang terkondensasi serta minyak yang berasal dari proses pirolisis.

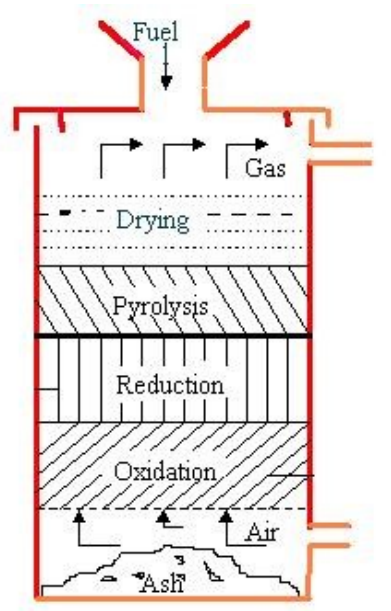

\section{Gambar 1. Skema reaktor gasifikasi tipe updraft}

Tar diasumsikan sebagai phenol, toluene, benzene, xylene dan ethylbenzene. Pada reaktor Gasifikasi tipe updraft mempunyai kandungan tar yang realatif tinggi, sekitar $2,8 \%$ berat karena terbawanya gas hasil pyrolysis (J. Pecho et all ; 2008).

Tar primer diproduksi selama proses pirolisis primer. Tar ini terdiri dari oxygenated, organik primer, dan molekul terkondensasi. Produk utama berasal dari terurainya komponen-komponen selulosa, hemiselulosa, dan lignin dari biomassa. (Milne dkk ; 1998) mendaftarkan sejumlah besar senyawa asam, gula, alkohol, keton, aldehid, fenol, guaiacols, syringols, furan, dan campuran oxygnates dalam tar ini. Jenis tar inilah yang terbentuk pada updraft gasifikasi yang terbentuk dalam rentang temperatur $200{ }^{\circ} \mathrm{C}-500{ }^{\circ} \mathrm{C}$.

Pengukuran tar dimaksud untuk mengetahui massa tar per satuan volume gas dan jenis tar yang dihasilkan dari reaktor gasifikasi. Banyak metode untuk mengetahui kadar atau konsentrasi tar pada gas produk, seperti contohnya melakukan sampling terhadap gas dengan menggunakan tabung-tabung impinger, analisa spektografi dengan menggunakan 
photo-ionization detector, ataupun dengan metode-metode lainnya. Namun demikian, penulis memutuskan untuk menggunakan metode gas sampling yang telah terstandardisasi yaitu berpegang pada Guidline for Sampling and Analysis of Tar and Particles in Biomass Producer Gases yang telah mendapat standar CEN (ComiteEuropeen de Normalisation) dan mempunyai range ukur yang besar yaitu 1 $\mathrm{mg} / \mathrm{m}^{3}$ - $300 \mathrm{~g} / \mathrm{m}^{3}$ satuan volume gas produser. Hal ini dikarenakan tar yang akan diukur adalah jenis tar primer yang terkandung dalam gas dengan konsentrasi yang tinggi.

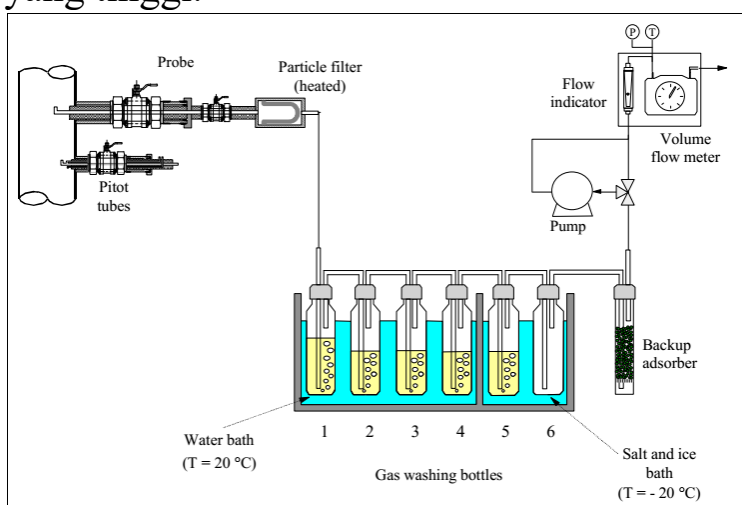

Gambar 2. Skema proses pengambilan tar menggunakan tabung impinger

Untuk Menghitung banyaknya sampel gas (dalam satuan liter) yang ditarik selama pengujian dilakukan, dapat di hitung dengan persamaan berikut.

$$
V \text { gas }=Q \times t=\text { liter }
$$

Dimana :

$\mathrm{V}$ gas = banyak sampel gas (liter)

$\mathrm{Q}=$ Debit aliran penarikan gas sampel (liter/menit)

$\mathrm{t}=$ Lama waktu pengujian (menit)

Menghitung banyaknya massa tar yang dihasilkan untuk setiap liter gas sampel.

$$
\begin{array}{r}
\text { M tar }=\frac{\text { M total }}{\text { V gas }} \\
=\text { gram } / \text { liter }
\end{array}
$$

Dimana :

M tar = Massa tar dalam satu liter gas sampel (gram/liter)

$\begin{array}{ll}\mathrm{M} \text { total } & =\text { Massa total tar (gram) } \\ \mathrm{V} \text { gas } & =\text { Banyak sampel gas (liter) }\end{array}$
Rotary evaporator ialah alat yang biasa digunakan di laboratorium kimia untuk mengefisienkan dan mempercepat pemisahan pelarut dari suatu larutan. Alat ini menggunakan prinsip vakum destilasi, sehingga tekanan akan menurun dan pelarut akan menguap dibawah titik didhnya. Rotary evaporator sering digunakan dibandingkan dengan alat lain yang memiliki fungsi sama karena alat ini mampu menguapkan pelarut dibawah titik didih sehingga zat yang terkandung di dalam pelarut tidak rusak oleh suhu tinggi.

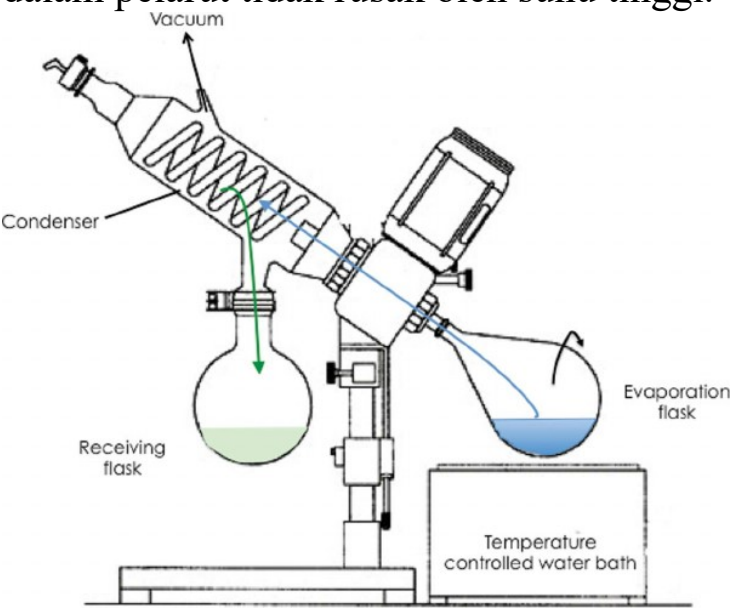

Gambar 3. Skema Rotary Evaporator

Untuk melakukan proses pembakaran pada pada bahan bakar yang ada didalam reaktor gasifikasi, maka dibutuhkan blower untuk mensuplai udara kedalam raktor.pembakaran.

Seberapa besar kandungan udara yang dibutuhkan untuk melakukan proses gasifikasi ini dapat diketahui dengan melakukan perhitungan stoikiometrik pada reaksi pembakaran pada bahan bakar yang akan digunakan nantinya dengan mereaksikannya dengan udara. Besaran satuan udara ini akan berbentuk satuan berat sehingga dengan melakukan pendekatan persamaan laju aliran massa maka akan di dapat kecepatan aliran udara yang akan dibutuhkan nantinya.

$$
\dot{\mathrm{m}}=\rho \cdot \mathrm{A} \cdot \mathrm{V} \ldots(3)
$$

Dmana :

m $\quad$ : Laju aliran massa $(\mathrm{kg} / \mathrm{s})$

$\rho \quad$ : Massa jenis $\left(\mathrm{kg} / \mathrm{m}^{3}\right)$

A : Luas penampang $\left(\mathrm{m}^{2}\right)$ 
V : Kecepatan $(\mathrm{m} / \mathrm{s})$

Debit aliran udara yang akan diberikan oleh blower ke reaktor gasifikasi perlu untuk diketahui. Hal ini berhubungan dengan menentukan besarnya Ekivalen Rasio (ER) udara yang akan diberikan nantinya. Untuk mengetahui berapa besarnya debit aliran yang akan dihasilkan oleh blower maka kecepatan aliran massa udara harus diketahui terlebih dahulu dengan menggunakan alat Anemometer.

Sehingga Debit Aliran dapat diketahui dengan persamaan,

$$
Q=A \cdot V
$$

Dimana :

Q : Debit aliran $\left(\mathrm{m}^{3} / \mathrm{s}\right)$

A : Luas penampang $\left(\mathrm{m}^{2}\right)$

$\mathrm{V} \quad$ : Kecepatan $(\mathrm{m} / \mathrm{s})$

Pada umunya flow meter aliran berdasarkan tekanan ini menggunakan prinsip beda tekanan Bernoulli. Metoda ini berdasarkan Hukum Bernoulli yang menyatakan hubungan :

$$
\begin{aligned}
p 1+\frac{1}{2} \rho v 1^{2} & +\rho \cdot g \cdot h 1 \\
& =p 2+\frac{1}{2} \rho v 2^{2} \\
& +\rho \cdot g \cdot h 2 \quad \ldots
\end{aligned}
$$

Dimana :

$$
\begin{array}{ll}
\mathrm{P} & =\text { Tekanan Fluida } \\
\rho & =\text { masa jenis fluida } \\
\mathrm{v} & =\text { Kecepatan fluida } \\
\mathrm{g} & =\text { Gravitasi bumi } \\
\mathrm{h} & =\text { Tinggi fluida }
\end{array}
$$

Jumlah fluida yang mengalir per satuan waktu $\left(\mathrm{m}^{3} / \mathrm{s}\right)$ adalah :

Dimana :

$$
Q=\frac{\Delta P \cdot A}{\rho \cdot g \cdot t}
$$

$\mathrm{Q}=$ Jumlah fluida yang mengalir $\left(\mathrm{m}^{3} / \mathrm{s}\right)$

$\Delta \mathrm{P} \quad=$ Perubahan tekanan $(\mathrm{Pa})$

A $\quad=$ Luas penampang $\left(\mathrm{m}^{2}\right)$

$\rho \quad=$ Massa jenis fluida $\left(\mathrm{kg} / \mathrm{m}^{3}\right)$

$\mathrm{g} \quad=$ gravitasi bumi $\left(\mathrm{m} / \mathrm{s}^{2}\right)$

$\mathrm{t} \quad=$ waktu (s)

\section{METODE PENELITIAN}

Proses Pengujian dilakukan selama 2 hari pada masing-masing 2 jenis biomassa yang akan di teliti, hari pertama bahan bakar yang digunakan adalah Tempurung Kelapa, hari kedua bahan bakar yang digunakan adalah Pelepah kelapa sawit. Setelah semua alat dan bahan tersedia Proses gasifikasi dapat dilakukan, pertama masukkan $2 \mathrm{~kg}$ bahan bakar kedalam reaktor, langkah selanjutnya adalah menyulut syngas sampai di peroleh nyala api yang stabil lalu hidupkan stopwatch untuk mengukur waktu lama nyala api. Proses pengambilan tar dilakukan selama nyala api yang dihasilkan reaktor gasifikasi masih menyala dan stabil, ketika nyala api pada reaktor padam, maka pengambilan tar dihentikan.

\section{Alat dan bahan :}

Reaktor gasifikasi yang dipakai adalah reaktor gasifikasi tipe updraft milik Laboraturium Teknik Mesin Universitas Muhammadiyah Riau.

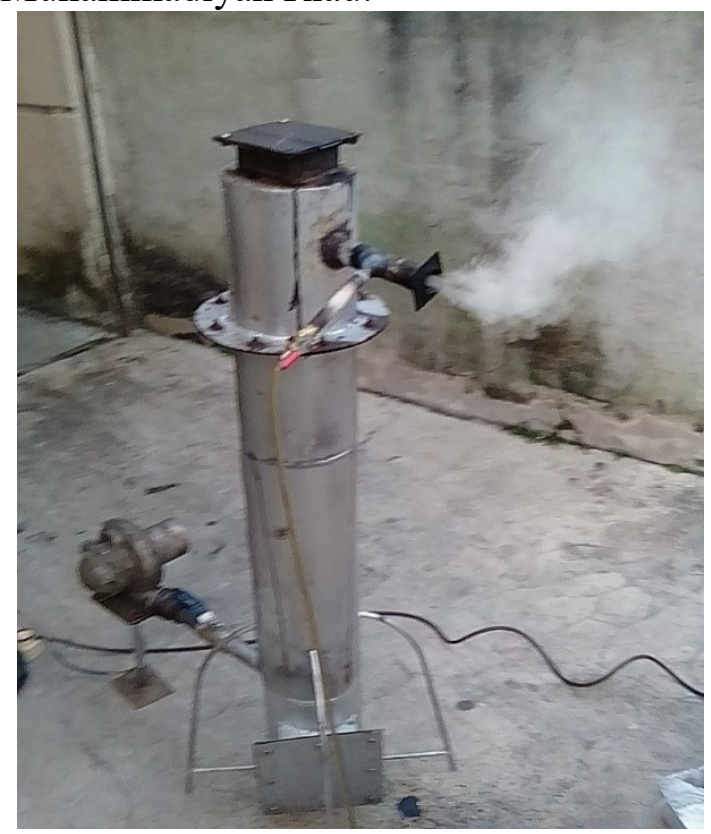

Gambar 4. Reaktor Gasifikasi tipe updraft Laboraturium Teknik Mesin Universitas Muhammadiyah Riau 


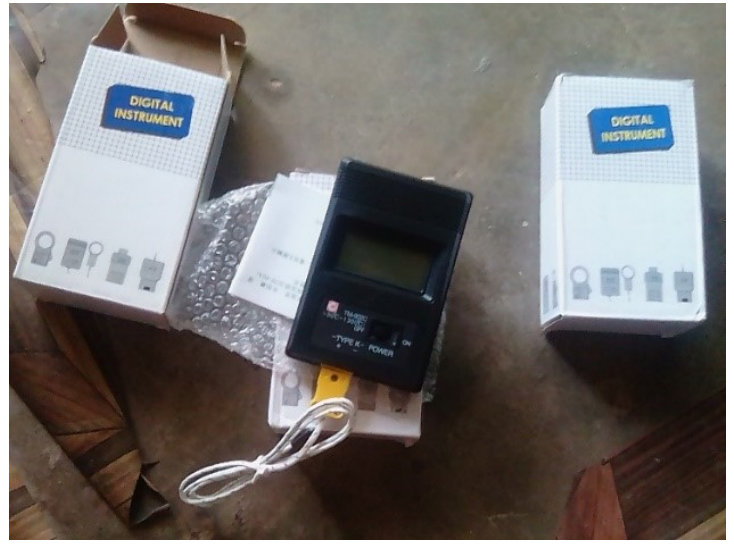

Gambar 5. Termokopel tipe K

Timbangan digital digunakan untuk mengukur berat Tar yang dihasilkan dari Reaktor Gasifikasi.

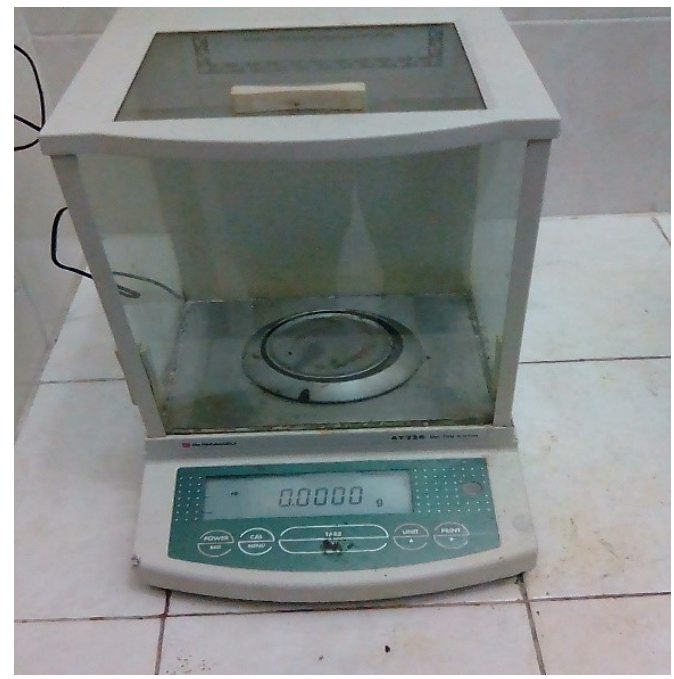

Gambar 6. Timbangan digital

Tabung impinger yang digunakan sebanyak 7 buah. Tabung Impinger terbuat dari botol minuman vitamin bekas, tutup botol dilubangi kemudian dimasukkan selang, 1 selang panjang dan 1 selang pendek. 5 Tabung impinger diisi dengan cairan Isopropanol (Isopropyl Alcohol) 1 Tabung diisi kapas dan 1 Tabung dibiarkan kosong.

Kotak kondensasi 1 kotak plastik yang nanti akan diisi oleh air dan 4 buah tabung impinger, suhu dijaga $20{ }^{0} \mathrm{C}$. Kotak kondensasi 2 kotak plastik yang nanti akan diisi oleh es batu dan 2 buah tabung impinger, kotak kondensasi 2 dilapisi dengan alumunium foil dan dijaga suhunya $-20{ }^{0} \mathrm{C}$.

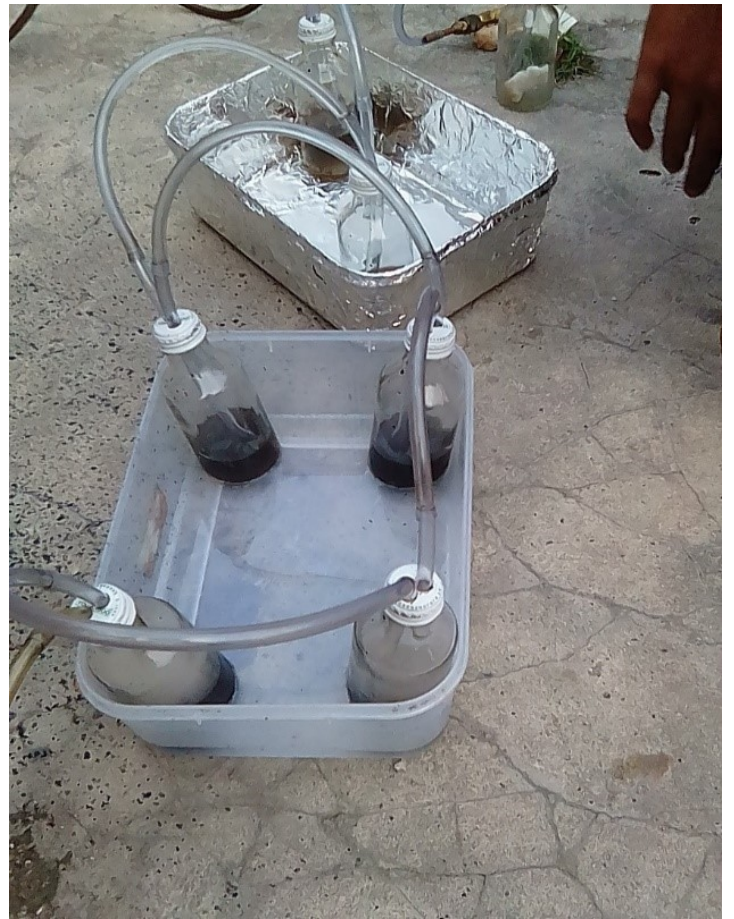

Gambar 7. Tabung Impinger dan Kotak Kondensasi

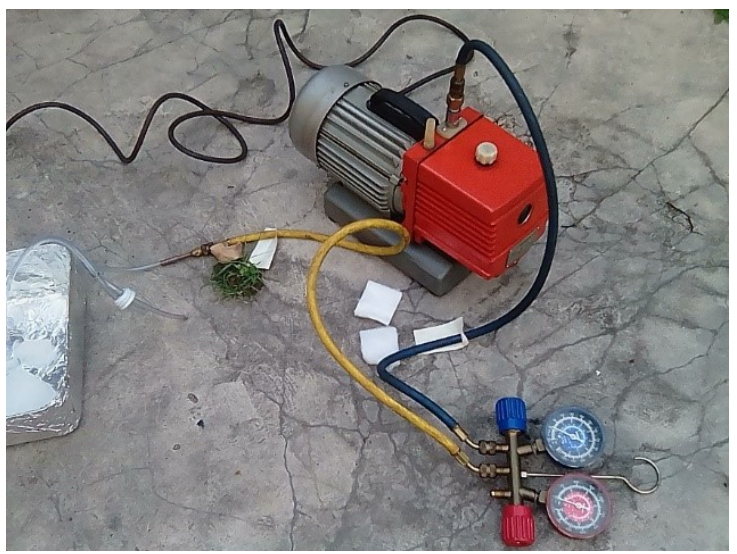

Gambar 8. Pompa vakum

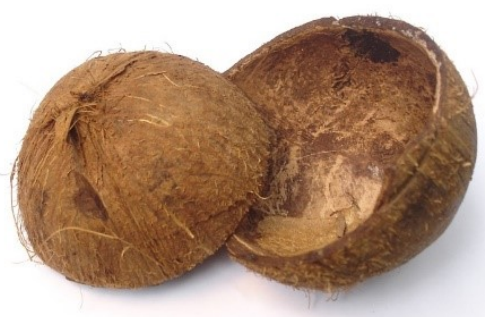

(a) 


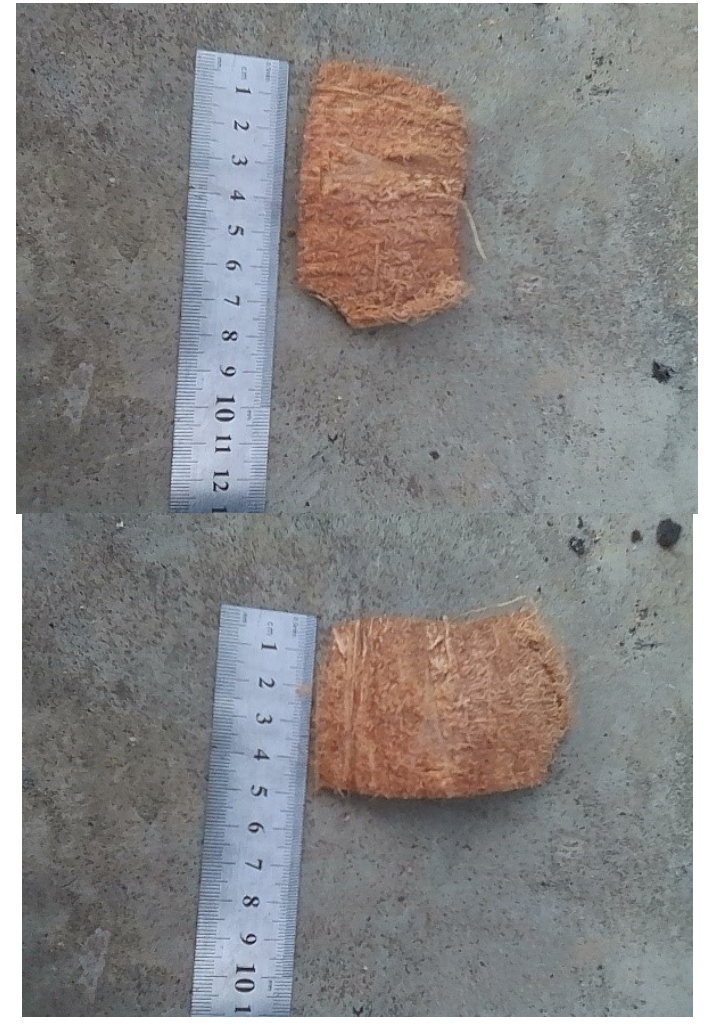

(b)

Gambar 9. a) Tempurung kelapa, b) Tempurung Kelapa yang sudah dicacah dan dibuat dimensinya menjadi $7 \times 5 \mathrm{~cm}$.

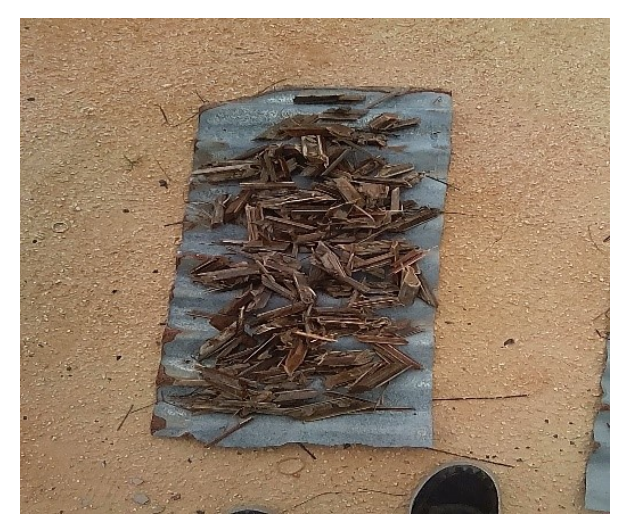

(a)

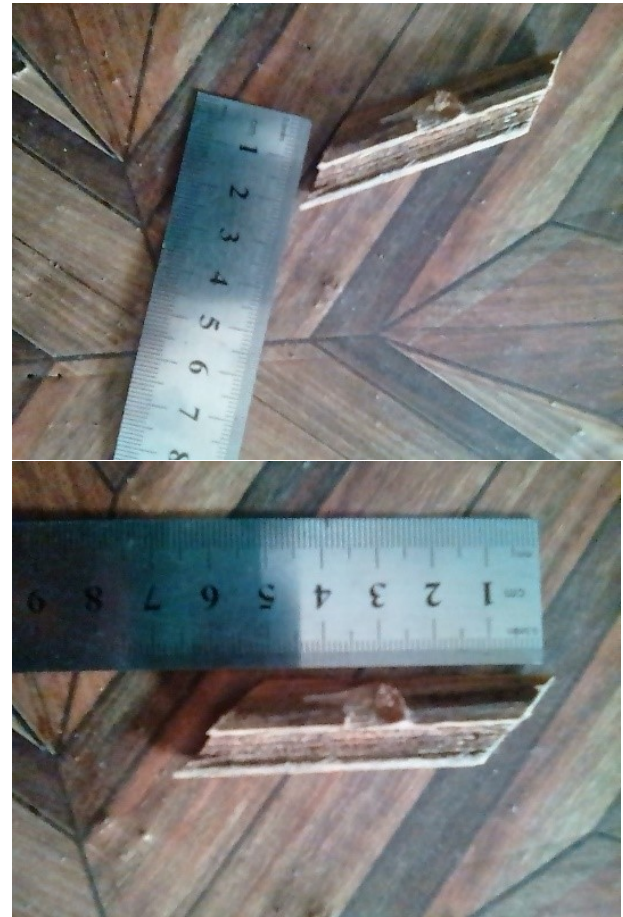

(b)

Gambar 10. a) Pelepah kelapa sawit, b)Pelepah Kelapa sawit yang sudah dicacah dan dibuat dimensinya $5 \times 2 \mathrm{~cm}$.

Solvent atau yang disebut dengan pelarut berfungsi sebagai penangkap Tar yang terdapat dalam gas sampel. Solvent yang digunakan pada penelitian ini adalah isopropanol.

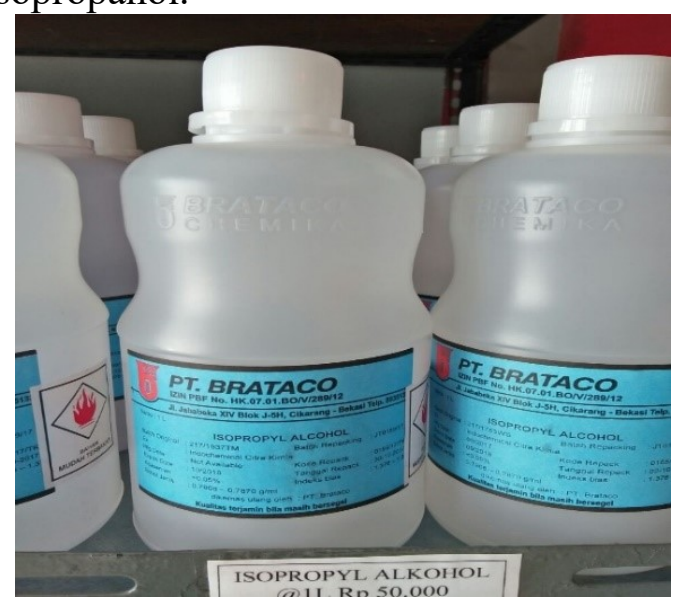

Gambar 11. Isopropanol (Isopropyl Alcohol) 


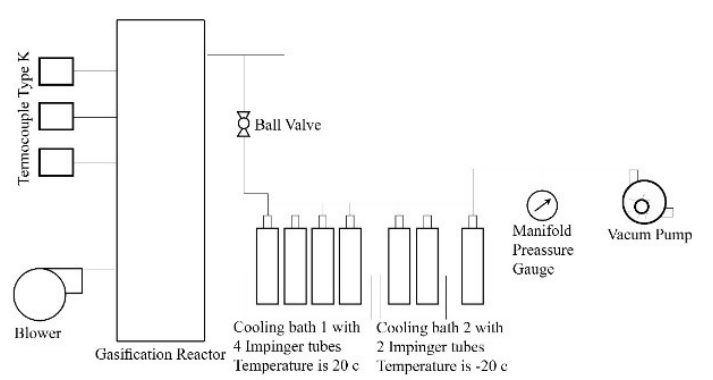

Gambar 12. Skema alat pengujian

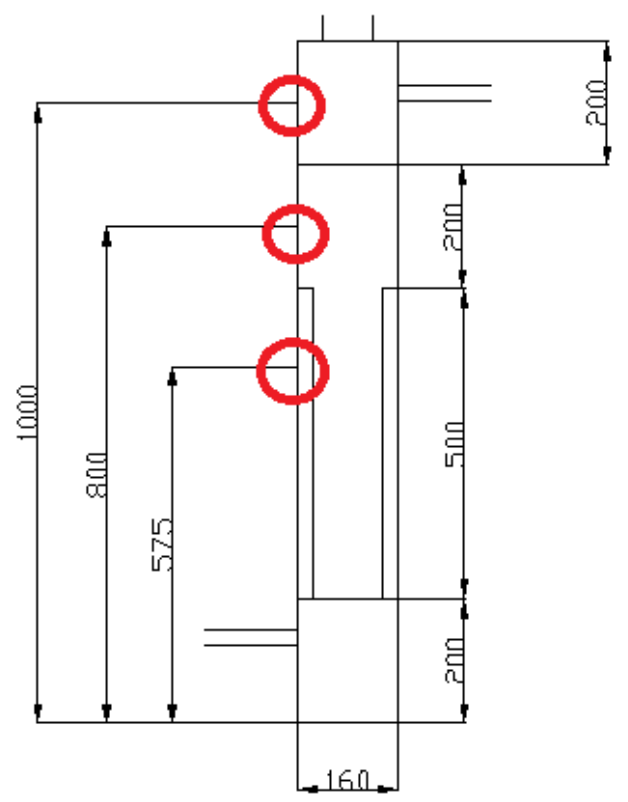

Gambar 13. SkemaTitik-titik peletakan Termokopel

\section{HASIL DAN PEMBAHASAN}

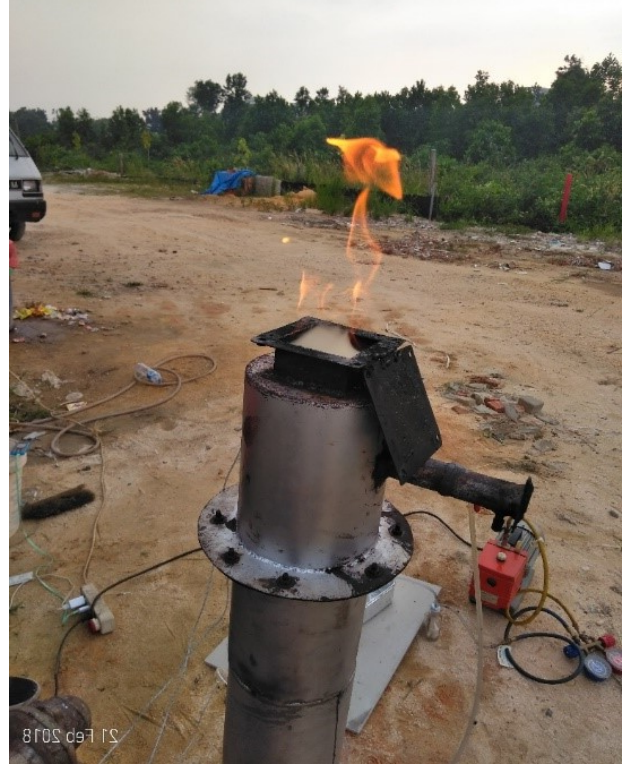

Gambar 14. Syngas yang dihasilkan pada saat penelitian
Tabel 1. Data penelitian mampu nyala syngas

\begin{tabular}{|c|c|c|}
\hline Parameter & Tempurung Kelapa & Pelepah Kelapa Sawit \\
\hline $\begin{array}{c}\text { Dimensi (panjang } \mathrm{x} \\
\text { lebar) }(\mathrm{cm})\end{array}$ & $7 \times 5$ & $5 \times 2$ \\
\hline Moisture Content $(\%)$ & 15 & 20 \\
\hline Temperatur Syngas $\left({ }^{\circ} \mathrm{C}\right)$ & 76,4 & 71,8 \\
\hline Lama Nyala (menit) & 43,14 & 10,26 \\
\hline ER optimum & 0,17 & 0,62 \\
\hline
\end{tabular}

Distribusi Temperatur terhadap waktu Biomassa Tempurung Kelapa

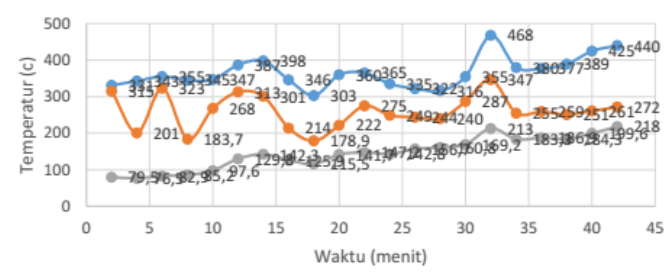

$\multimap \mathrm{T} 1 \rightarrow \mathrm{T} 2 \rightarrow \mathrm{T} 3$

Gambar 15. Grafik Distribusi temperatur Biomassa Tempurung kelapa

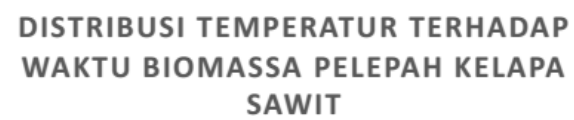
SAWIT

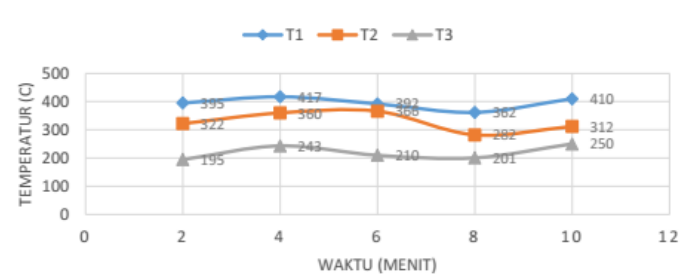

Gambar 16. Grafik Distribusi temperatur biomassa Pelepah kelapa sawit

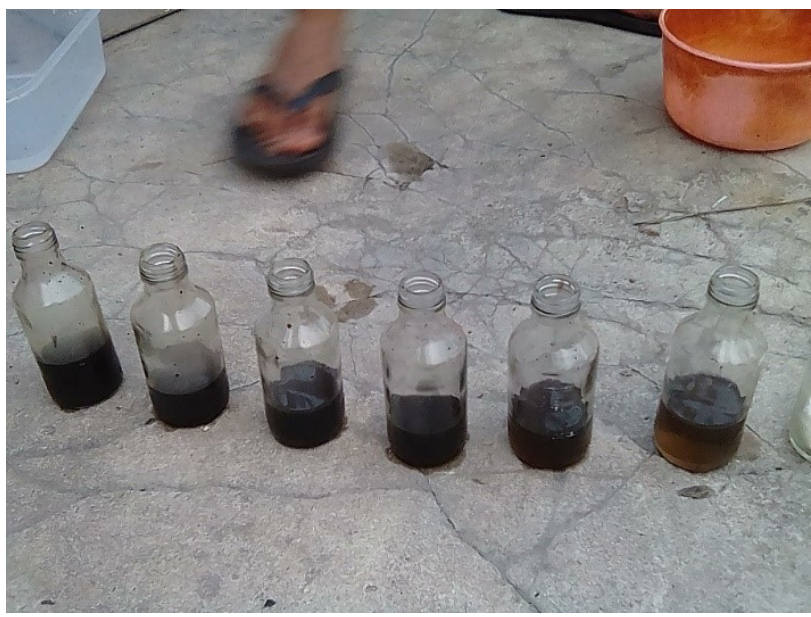

Gambar 17. Tar yang dihasilkan pada reaktor gasifikasi sebelum disatukan 
Tabel 2. Data penimbangan tar

\begin{tabular}{|c|c|c|c|}
\hline Nama Biomassa & $\begin{array}{c}\text { Berat wadah } \\
\text { kosong }\left(\mathrm{m}_{1}\right)\end{array}$ & $\begin{array}{c}\text { Berat wadah } \\
\text { berisi tar }\left(\mathrm{m}_{2}\right)\end{array}$ & $\begin{array}{c}\text { Berat tar total } \\
\left(\mathrm{m}_{2}-\mathrm{m}_{1}\right)\end{array}$ \\
\hline $\begin{array}{c}\text { Tempurung } \\
\text { kelapa }\end{array}$ & $116,25 \mathrm{~g}$ & $125,24 \mathrm{~g}$ & $8,99 \mathrm{~g}$ \\
\hline $\begin{array}{c}\text { Pelepah kelapa } \\
\text { sawit }\end{array}$ & $119,14 \mathrm{~g}$ & $123,76 \mathrm{~g}$ & $4,62 \mathrm{~g}$ \\
\hline
\end{tabular}

Untuk mengetahui berapa banyak sampel gas (dalam satuan liter) yang ditarik selama pengujian dilakukan, dapat dihitung dengan persamaan berikut.

$$
V \text { gas }=Q \times t=\text { liter }
$$

Pada penelitian ini alat ukur yang digunakan adalah manifold pressure gauge yang merupakan alat pengukur tekanan, maka dari itu perlu dihitung debit aliran penarikan gas sampel dengan menggunakan persamaan Debit aliran berdasarkan differensial tekanan.

\section{Perhitungan sampel gas tar Tempurung kelapa}

Diketahui :

$$
\begin{array}{ll}
\mathrm{D} & =0,00635 \mathrm{~m} \\
\mathrm{P} 1 & =0 \mathrm{inHg}=0 \mathrm{~Pa} \\
\mathrm{P} 2 & =-15 \mathrm{inHg}=-50795,82 \mathrm{~Pa} \\
\mathrm{~g} & =9,81 \mathrm{~m} / \mathrm{s}^{2} \\
\mathrm{t} & =43,14 \text { menit }=2588,4 \mathrm{~s}
\end{array}
$$

dimana :

D adalah diameter pipa silikon $1 / 4$ inchi.

P1 dan P2 adalah perubahan tekanan yang diukur dari Manifold Pressure Gauge.

Asumsikan densitas syngas ( $\rho) \quad 1,1827$ $\mathrm{kg} / \mathrm{m}^{3}$

$$
\begin{aligned}
A=\frac{1}{4} \pi \cdot D^{2}= & \frac{1}{4} \cdot 3,14 \cdot(0,00635)^{2} \\
& =3,16 \cdot 10^{-5} \mathrm{~m}^{2}
\end{aligned}
$$

Maka debit aliran penarikan gas dapat dihitung.

$$
\begin{gathered}
Q=\frac{\Delta P \cdot A}{\rho \cdot g \cdot t} \\
Q=\frac{\left(0-(-50795,82) \times 3,16 \cdot 10^{-5}\right.}{1,1827 \times 9,81 \times 2588,4} \\
Q=5,35 \cdot 10^{-5} \mathrm{~m}^{3} / \mathrm{s} \\
Q=3,21 \text { liter } / \text { menit }
\end{gathered}
$$

Maka V gas dapat dihitung.

$$
\begin{gathered}
V \text { gas }=Q \times t \\
V \text { gas }=3,21 \times 43,14=138,58 \text { liter }
\end{gathered}
$$

Maka $\mathrm{M}$ tar dapat dihitung.

$$
\begin{gathered}
M \text { tar }=\frac{M \text { total }}{V \text { gas }} \\
M \text { tar }=\frac{8,99}{138,58} \\
M \text { tar }=0,064 \text { gram } / \text { liter }
\end{gathered}
$$

\section{Perhitungan sampel gas Pelepah kelapa sawit}

Diketahui :

$$
\begin{array}{ll}
\mathrm{D} & =0,00635 \mathrm{~m} \\
\mathrm{P} 1 & =0 \mathrm{inHg}=0 \mathrm{~Pa} \\
\mathrm{P} 2 & =-15 \mathrm{inHg}=-50795,82 \mathrm{~Pa} \\
\mathrm{~g} & =9,81 \mathrm{~m} / \mathrm{s}^{2} \\
\mathrm{t} & =10,62 \text { menit }=637,2 \mathrm{~s}
\end{array}
$$

dimana :

D adalah diameter pipa silikon $1 / 4$ inchi.

P1 dan P2 adalah perubahan tekanan yang diukur dari Manifold Pressure Gauge.

Asumsikan densitas syngas ( $\rho) \quad 1,1827$ $\mathrm{kg} / \mathrm{m}^{3}$

$$
\begin{aligned}
A=\frac{1}{4} \pi \cdot D^{2}= & \frac{1}{4} \cdot 3,14 \cdot(0,00635)^{2} \\
& =3,16 \cdot 10^{-5} \mathrm{~m}^{2}
\end{aligned}
$$

Maka debit aliran penarikan gas dapat dihitung.

$$
\begin{gathered}
Q=\frac{\Delta P \cdot A}{\rho \cdot g \cdot t} \\
Q=\frac{\left(0-(-50795,82) \times 3,16 \cdot 10^{-5}\right.}{1,1827 \times 9,81 \times 637,2} \\
Q=2,17 \cdot 10^{-4} \mathrm{~m}^{3} / \mathrm{s} \\
Q=13,04 \text { liter } / \text { menit }
\end{gathered}
$$

Maka V gas dapat dihitung.

$$
V \text { gas }=Q \times t
$$


$V$ gas $=13,04 \times 10,62=133,88$ liter

Maka $\mathrm{M}$ tar dapat dihitung.

$$
\begin{aligned}
& M \text { tar }=\frac{M \text { total }}{V \text { gas }} \\
& M \operatorname{tar}=\frac{4,62}{133,88}
\end{aligned}
$$

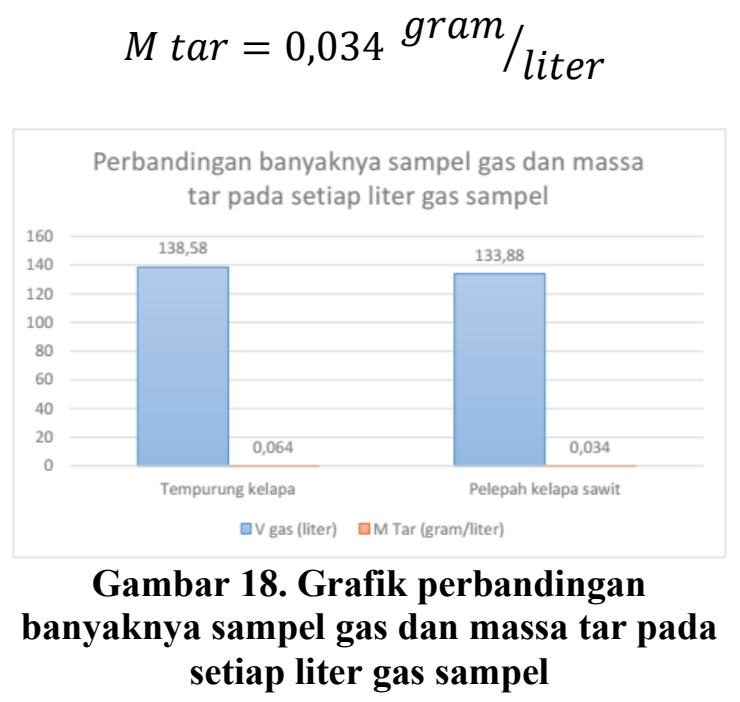

Berdasarkan gambar 4.9 terlihat, banyaknya sampel gas yang disedot pompa vakum pada biomassa Tempurung kelapa adalah sebesar 138,58 liter sedangkan pada biomassa Pelepah kelapa sawit 133,88 liter.Massa Tar pada setiap liter gas sampel biomassa Tempurung kelapa adalah sebesar 0,064 gram/liter sedangkan pada biomassa Pelepah kelapa sawit 0,034 gram/liter. Ini berarti densitas tar Tempurung kelapa yang dihasilkan dari proses gasifikasi lebih besar daripada Pelepah kelapa sawit.

\section{KESIMPULAN}

Berdasarkan data dan analisa penelitian, maka dapat ditarik kesimpulan sebagai berikut :

1. Biomassa Tempurung Kelapa mampu menghasilkan syngas lebih lama daripada Pelepah kelapa sawit yakni selama 43 menit 14 detik. Sedangkan Pelepah kelapa sawit hanya mampu menghasilkan syngas selama 10 menit 26 detik. Ini merupakan pengaruh dari persentase moisture content biomassa Pelepah kelapa sawit lebih besar daripada Tempurung kelapa. Selain itu juga dipengaruhi oleh besarnya nilai kalor biomassa, yang mana nilai kalor Tempurung kelapa lebih besar daripada nilai kalor Pelepah kelapa sawit.

2. Berat tar kering Tempurung kelapa yang ditimbang menggunakan timbangan digital adalah sebesar 8,99 g, sedangkan Berat tar kering Pelepah kelapa sawit yang ditimbang menggunakan timbangan digital adalah sebesar $4,62 \mathrm{~g}$.

3. Banyaknya sampel gas yang disedot pompa vakum pada biomassa Tempurung kelapa adalah sebesar 138,58 liter sedangkan pada biomassa Pelepah kelapa sawit hanya 133,88 liter.

4. Massa Tar pada setiap liter gas sampel biomassa Tempurung Kelapa adalah sebesar 0,064 gram/liter sedangkan pada biomassa Pelepah Kelapa Sawit hanya 0,034 gram/liter.

\section{DAFTAR PUSTAKA}

Abrar.R, M.Yunus " Perancangan dan Pembuatan tungku gasifikasi tipe updraft dengan variasi bahan bakar kayu terhadap lama penyalaan api“ Fakultas Teknik Universitas Muhammadiyah Riau 2014.

A'isyatul. K., 2015, "Karakteristik Api Syngas pada Gasifikasi Sistem Downdraft dengan Oksigen sebagai Gasyfaying Agent Berbahan Baku Biomassa”, Fakultas Teknik Universitas Jember.

Ade.H, 2013, "Karakteristik Proses Gasifikasi Biomassa pada Reaktor Downdraft Sistem Batch dengan Variasi Air-Fuel Ratio (AFR) dan Ukuran biomassa". Fakultas Teknik Universitas Gadjah Mada. 
Adi. S., Fajri. V., Yulianto. S. N., 2014, "Experimental Gasification of Biomass in an Updraft Gasifier with External Recirculation of Pyrolysis Gases", Journal of Combustion, Vol. 2014, Hindawi Publishing Corporation.

Arief. T., 2015, "Panduan Penilaian Potensi Biomassa Sebagai Sumber Energi Alternatif di Indonesia", Penabulu Alliance.

Bambang. S., Daniar. B. M., Dita. F. W., 2009, "Karakterisasi Gasifikasi Biomassa Sekam Padi Menggunakan Reaktor Downdraft dengan Dua Tingkat Laluan Udara", Seminar Nasional Tahunan Teknik Mesin (SNTTM) ke-8, Agustus.

Daniel. T. P., Einara. B. M., Jose. L. S., Yasuyuki. N., 2013, "Experimental Study of Bottom Feed Updraft Gasifier". Elsevier.

Dede.Y, 2016, “Analisa Pengaruh kandungan Tar pada Gasifikasi type Updraft Terhadap Perlakuan Udara Panas Masuk Reaktor dan Variasi ER (Ekivalen Rasio)". Universitas Muhammadiyah Riau, Pekanbaru.

Dyizad. D., 2013, "Simulasi Numerik Untuk Memprediksi Kinerja Reaktor Gasifikasi Sabut Kelapa Tipe Downdraft", Fakultas Teknologi Pertanian Institut Pertanian Bogor.

Fajri. V., 2008, "Gasifikasi Tempurung Kelapa Menggunakan Updraft Gasifier pada beberapa variasi Laju Aliran Udara Pembakaran”, Jurnal Teknik Mesin, Vol. 10, Oktober.

Fiseha. M. G., Shaharin. A. S., Anita. R., 2014, "Study of The Effects of Operating Factors on The Resulting Producer Gas of Oil Palm Fronds Gasification with a Single Throat Downdraft Gasifier", Elsevier.
Gede. H. G., Made. S., Nyoman. S. W., 2015, "Analisis Performansi Reaktor Gasifikasi Updraft dengan Bahan Bakar Tempurung Kelapa", Jurnal METTEK, Vol. 1 No.2.

Handbook of Gasification Technologies A Primer for Engineers and Scientists Chemical Industries. 2005. Taylor \& Francis Group, LLC.

Irvan. N, 2012, "Studi Kandungan Tar Updraft Gasifier Dengan Pengeluaran Syngas Pada Zona Reduksi", Universitas Indonesia

Kai Wu., Tianqi. R., Haijun. C., Yuezhao. Z., 2017, "Experimental Investigation of Whole Tires and Biomass Mixed Firing in Reverse Burning Fixed-bed Gasifier", Elsevier.

Lailun. N., Sudjud. D., 2012, "Karakterisasi Proses Gasifikasi Biomassa Tempurung Kelapa Sistem Downdraft Kontinyu dengan Variasi Perbandingan Udara-Bahan Bakar (AFR) dan Ukuran Biomassa", Jurnal Teknik ITS, Vol.1 No. 1, September.

Michael, J. M., Howard, N. S., Fundamentals of Engineering Thermodynamics, 5th edition, John Wiley \& Sons, Inc., USA.

Basu, Prabir, 2010, "Biomass Gasification and Pyrolisis Practical Design, UK: Elsevier.

Raphael, I. M., John, P. J., Masoud, M. K., 2015, "The Effect of Using Biomass Gasification as Source of Energy to Small Scale Bio-ethanol Production", International Journal of Engineering Research and Reviews, Vol.3, January.

Samson. M. A., Shaharin. A. S., Suzana. Y., 2013, "Syngas Production from Downdraft Gasification of Oil Palm Fronds", Elsevier. 
Samsudin. A., Z. A. Zainal., 2011, "Tar Reductiun in Biomass Producer Gas Via Mechanical, Catalytic and Thermal Methods: A Review", Elsevier.
Shunsuke. N., Shigeru. K., Kunio. Y., 2016, "Biomass Gasification Process with The Tar Removal Technologies Utilizing Bio-oil Scrubber and Char Bed", Elsevier. 